\title{
Identifying diabetics in Medicare claims and survey data: implications for health services research
}

\author{
Joseph W Sakshaug ${ }^{1,2^{*}}$, David R Weir ${ }^{1}$ and Lauren H Nicholas ${ }^{3}$
}

\begin{abstract}
Background: Diabetes health services research often utilizes secondary data sources, including survey self-report and Medicare claims, to identify and study the diabetic population, but disagreement exists between these two data sources. We assessed agreement between the Chronic Condition Warehouse diabetes algorithm for Medicare claims and self-report measures of diabetes. Differences in healthcare utilization outcomes under each diabetes definition were also explored.

Methods: Claims data from the Medicare Beneficiary Annual Summary File were linked to survey and blood data collected from the 2006 Health and Retirement Study. A Hemoglobin A1c reading, collected on 2,028 respondents, was used to reconcile discrepancies between the self-report and Medicare claims measures of diabetes. T-tests were used to assess differences in healthcare utilization outcomes for each diabetes measure.

Results: The Chronic Condition Warehouse (CCW) algorithm yielded a higher rate of diabetes than respondent self-reports (27.3 vs. 21.2, $p<0.05)$. A1c levels of discordant claims-based diabetics suggest that these patients are not diabetic, however, they have high rates of healthcare spending and utilization similar to diabetics.

Conclusions: Concordance between A1c and self-reports was higher than for A1c and the CCW algorithm. Accuracy of self-reports was superior to the CCW algorithm. False positives in the claims data have similar utilization profiles to diabetics, suggesting minimal bias in some types of claims-based analyses, though researchers should consider sensitivity analysis across definitions for health services research.
\end{abstract}

Keywords: Diabetes, Survey data, Medicare claims, Chronic condition warehouse

\section{Background}

Diabetes has become one of the most common and expensive medical conditions amongst older adults. Nearly $25 \%$ of all adults ages 60 and older have diabetes in the United States [1] and this group accounts for over half of the more than $\$ 100$ billion in healthcare expenditures attributable to this disease [2]. Reducing the disease and economic burden of diabetes has been a long-standing goal in health policy.

Carefully designed analyses of secondary datasets, including Medicare claims data, can contribute to diabetes health services research. The strength of this design is

\footnotetext{
*Correspondence: joesaks@umich.edu

'Institute for Social Research, University of Michigan, 426 Thompson Street,

Ann Arbor, Ml 48104, USA

${ }^{2}$ Institute for Employment Research, Regensburger Str. 104, Nuremberg

90478, Germany

Full list of author information is available at the end of the article
}

critically dependent on being able to identify diabetic patients in datasets. Utilization-based algorithms are frequently used to identify chronic disease cohorts in national Medicare data and other administrative datasets. However, concordance between disease status assessed by these algorithms and patient self-reports can be low, raising concern about the bias associated with research designs relying on non-clinical data $[3,4]$.

A diabetes diagnosis requires clinical measures of Hemoglobin A1c (the gold standard since 2010), a measure of blood sugar control over the past 60-90 days, or fasting blood sugar [5]. However, obtaining clinical measures of diabetes status for health services research is rare, and most researchers rely on more subjective measures, such as selfreports or claims-based diagnoses to identify the diabetic population. Both measures have strengths and limitations.

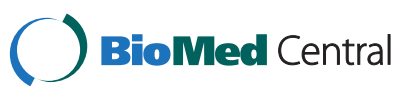


Self-reports are commonly used to assess diabetes prevalence in survey data when biological measures are unavailable [6-9]. Self-reports are believed to underestimate diabetes prevalence because they depend on a patient seeing a doctor to receive a clinical diagnosis and correctly reporting when asked. The standard approach in surveys with biomarkers is to take all self-reports as true cases and add in the people who self-report "no" but test above the diagnostic threshold. The National Health and Nutrition Examination Survey (NHANES) is the most common data source used for studying the population of undiagnosed diabetics. The latest published NHANES estimates for the 65 and older population for years 2003-2006 indicate a diabetes rate of $21.1 \%$ based on the sum of self-reported diabetics (17.7\%) and self-reported non-diabetics with an A1c reading greater than or equal to $6.5(3.5 \%)$ [10].

Claims-based diagnoses may be obtained from patient billing records, hospital discharge abstracts, and physician data and are usually based on algorithms that may or may not match actual diagnoses found in medical records [11]. The Center for Medicare and Medicaid Services' Chronic Condition Warehouse (CCW) algorithm is the primary diabetes algorithm used in Medicare claims-based research as it is included in their research files and many users are likely to implement it given inclusion in the Beneficiary Annual Summary File. The CCW algorithm defines a diabetic as someone who has had at least one inpatient, skilled nursing or home health visit or at least two outpatient visits with a diabetesrelated ICD-9 code during a two year period [12]. This definition was observed to be adequately sensitive $(\geq 70 \%)$ and reliable (kappa $\geq 0.80)$ [13]. Other studies of administrative claims-based measures of diabetes status have yielded varying sensitivities ranging from $64 \%$ to $87 \%$ when validated against different benchmarks, including laboratory data, medical records, and selfreports [4,14-16].

Investigating the quality of survey self-report and claimsbased diabetes measures is important because data users rely on these measures in health services research to produce population-based estimates of the diabetes population. These estimates often have important policy implications and any inaccuracies can lead to incorrect inferences. For example, overestimation of the diabetes population may lead to misleading conclusions about the quality of diabetes care as the false positives may be seen as not receiving adequate amounts of care. Conversely, underestimation of the diabetes population may lead to conclusions that understate the prevalence of the disease and the economic burden of the disease.

This paper provides some insight as to the accuracy of self-report and CCW claims-based diabetes measures and their implications for health services research. In it, we use nationally representative survey data linked to Medicare claims and measured Hemoglobin A1c levels from an in-person blood draw to compare the accuracy of the self-report and CCW measures relative to the A1c reading. Furthermore, we examine discrepancies between the two measures and compare commonly used healthcare utilization outcomes across each of the diabetes definitions.

\section{Methods}

We utilize the 2006 wave of the Health and Retirement Study (HRS) [17]. The HRS is a nationally representative longitudinal study of Americans over the age of 50. In 2006, HRS began collecting several physical measurements, including biologic specimens: saliva and dried blood spots. Here we focus on the collection of blood spots and measured Hemoglobin A1c to validate and understand discrepancies in self-reported and claimsbased diabetes status, which was obtained for 83 percent of the biomarker subsample who consented to the blood draw.

Medicare-eligible HRS respondents were asked for permission to link their Medicare records from the Centers for Medicare and Medicaid Services (CMS). HRS data and records from the 2006 Medicare Beneficiary

Table 1 Prevalence of Diabetes amongst Adults ages 65 and older in Three National Samples

\begin{tabular}{lcccc}
\hline & NHANES & Linked HRS/A1c & Linked HRS/Medicare & Linked HRS/Medicare/A1c \\
\hline Self-report & $19.1 \%(16.6-21.6)$ & $21.3 \%(19.8-22.8)$ & $21.7 \%(20.4-23.0)$ & $21.2 \%(19.2-23.2)$ \\
Hemoglobin A1c $\geq 6.5$ & $12.2 \%(10.1-14.3)$ & $13.0 \%(11.8-14.1)$ & - & $12.6 \%(10.7-14.4)$ \\
Undiagnosed & $3.8 \%(1.8-5.7)$ & $4.2 \%(3.3-5.2)$ & - & $4.4 \%(3.2-5.6)$ \\
Self-report + undiagnosed & $22.9 \%$ & $25.5 \%$ & - & $25.6 \%$ \\
Medicare claims & - & - & $28.7 \%(27.1-30.2)$ & $27.3 \%(25.3-29.2)$ \\
Sample size & 1,066 & 3,817 & 6,101 & 2,028 \\
\hline
\end{tabular}

Parenthetical entries are $95 \%$ confidence intervals.

Undiagnosed diabetes refers to the percentage of cases who self-reported not ever receiving a diabetes diagnosis but met the clinical threshold for diabetes ( $\mathrm{Ha} 1 \mathrm{c} \geq 6.5$ ).

Sources: 2006 Health and Retirement Study (HRS); 2006 Medicare Beneficiary Annual Summary File; 2005-2006 National Health and Nutrition Examination Survey (NHANES). 
Annual Summary Files were linked for 88 percent of respondents who consented to the linkage. Consent rates were higher for younger, wealthier, Hispanic, and nonwhite respondents. Diabetes prevalence is higher amongst minorities and the younger-old [2], suggesting that the self-selected subsample represents persons who are more likely to be diabetic.

Three measures of diabetes status were utilized: survey self-reports ("Has a doctor ever told you that you have diabetes or high blood sugar?"), indication of diabetes based on the Chronic Condition Warehouse (CCW) algorithm, and a Hemoglobin A1c score of 6.5 or higher [5].

Four healthcare utilization outcomes were extracted from the Medicare claims and used to assess differences between the diabetes definitions. The first three outcomes (total Medicare reimbursement, number of office visits, and number of hospitalizations in 2006) relate to general healthcare usage. The last outcome, the number of A1c tests ordered between years 2002-2005, is used as an indicator of quality of diabetes care, a commonly used measure in quality of care studies [18-21].

We restrict the sample to persons aged 65 years and older who were Medicare-eligible at the time of interview $(n=11,354)$. The sample was further restricted to individuals randomly selected for biomarker collection $(n=5,784)$, of which 3,820 completed the blood draw and received a valid A1c score. Of these cases, Medicare records were linked to 3,389 respondents. Beneficiaries who were not continuously enrolled in fee-for-service Medicare were excluded $(n=1,185)$ along with potential users of Veterans Affairs (VA) services to ensure that all health care utilization was reflected in the claims $(\mathrm{n}=176)$. The resulting analytic sample consisted of 2,028 respondents.

Concordance between the self-report and claims data was assessed using t-tests and two-way tables. Mean A1c levels and utilization outcomes are reported for the concordant and discordant cases. All analyses were performed using appropriate survey procedures in SAS

Table 2 Cross-classification of self-report and claims-based diabetes status

\begin{tabular}{lcc}
\hline & \multicolumn{2}{c}{ Medicare claims (\%) } \\
\hline Self-report (\%) & & Diabetic \\
Not diabetic & $71.1(1426)$ & $7.7(162)$ \\
Diabetic & $1.6(34)$ & $19.5(406)$ \\
\hline
\end{tabular}

Chi-square test statistic: $737.7 ; p<0.05$.

Cohen's Kappa statistic: 0.74 .

Parenthetical entries are sample sizes.

Claims-based diabetics are defined as those who have ever triggered the CCW definition for diabetes.

Sources: 2006 Health and Retirement Study (HRS); 2006 Medicare Beneficiary Annual Summary File.
Table 3 Percent of Medicare beneficiaries aged 65 and older, by Discordant (Claims) and Concordant Diabetes Classification Group and characteristics

\begin{tabular}{lcc}
\hline & $\begin{array}{c}\text { Claims-based } \\
\text { diabetics } \\
\text { (Discordant) }\end{array}$ & $\begin{array}{c}\text { Concordant diabetics } \\
\text { (Self-report and claims) }\end{array}$ \\
\hline Age & $34.0(3.7 ; 65)^{*}$ & $50.8(2.7 ; 230)^{*}$ \\
$65-74$ & $48.3(4.3 ; 72)$ & $39.5(2.5 ; 148)$ \\
$75-84$ & $17.8(3.3 ; 25)^{*}$ & $9.7(1.7 ; 28)^{*}$ \\
$85+$ & & \\
Gender & $39.5(4.2 ; 62)$ & $45.1(2.1 ; 184)$ \\
$\quad$ Male & & \\
Ethnicity & & $7.0(1.8 ; 34)$ \\
Hispanic & $4.4(1.7 ; 9)$ & \\
Race & & $10.2(1.5 ; 58)$ \\
Non-White & $13.8(2.8 ; 31)$ &
\end{tabular}

$\mathrm{HH}$ income

(quartiles of SR \&

Claims group)

$\begin{array}{lcc}\text { Q1 }(\$ 15,827 \text { or less }) & 30.1(3.8 ; 50) & 26.9(2.7 ; 102) \\ \text { Q2 }(\$ 15,828-\$ 30,576) & 21.7(4.0 ; 33) & 24.4(2.3 ; 100) \\ \text { Q3 }(\$ 30,577-\$ 49,438) & 22.0(4.5 ; 37) & 23.7(1.8 ; 102) ; \\ \text { Q4 }(\$ 49,439 \text { or more }) & 26.3(3.1 ; 42) & 25.0(2.6 ; 102) \\ \text { Health rating } & 29.9(3.2 ; 52)^{*} & 21.8(2.6 ; 91)^{*} \\ \text { Excellent/NG } & 36.7(3.4 ; 59) & 35.5(2.7 ; 144) \\ \text { Good } & 33.5(3.8 ; 51) & 42.8(4.1 ; 171) \\ \text { Fair/Poor } & & \\ \text { Moderate activity } & 45.8(3.5 ; 72) & 44.4(2.5 ; 175) \\ \text { Hardly ever/never } & & \\ \text { Number of diseases } & 14.8(2.7 ; 22) & 9.8(1.8 ; 40) \\ 0 & 41.4(3.4 ; 71) & 37.5(2.2 ; 163) \\ 1 & 24.5(3.9 ; 42) & 31.5(1.7 ; 124) \\ 2 & 19.3(3.6 ; 27) & 21.2(2.4 ; 79)\end{array}$

$3+$

Self-Reported Memory Rating

$\begin{array}{lcc}\text { Excellent/Nery good } & 16.7(2.8 ; 26) & 20.3(2.0 ; 82) \\ \text { Good } & 43.4(3.7 ; 71) & 44.2(2.2 ; 173) \\ \text { Fair/Poor } & 39.9(3.1 ; 65) & 35.5(3.0 ; 151)\end{array}$

Cognitive Functioning

(TICS Score)

$\begin{array}{lcc}0-8 & 23.1(4.3 ; 39) & 18.1(1.9 ; 68) \\ 9 & 21.4(3.7 ; 35) & 27.4(2.2 ; 111) \\ 10 & 55.5(5.1 ; 88) & 54.6(2.6 ; 227)\end{array}$

Total number of flagged diabetics

162

406

Notes: Standard errors and sample sizes are in parentheses.

Column percentages may not always add to 100 due to rounding error.

*Difference between self-report estimate and claims estimate is statistically significant $p<0.05$.

Source: 2006 Health and Retirement Study; 2006 Medicare Beneficiary Annual Summary File. 
Table 4 Hemoglobin A1c estimates by self-report and chronic condition warehouse diabetes status

\begin{tabular}{lcccc}
\hline Clinical measures & Self-report, yes; Claims, yes & Self-report, yes; Claims, no & Self-report, no; Claims, yes & Self-report, no; Claims, no \\
\hline Hemoglobin A1c (mean) & $6.60(0.05)$ & $6.32(0.03)$ & $5.86(0.04)$ & $5.64(0.02)$ \\
Hemoglobin A1c $\geq 6.5(\%)$ & $45.7(2.4)$ & $30.5(0.5)$ & $12.4(2.2)$ & $3.5(0.6)$ \\
Hemoglobin A1c $<6.0(\%)$ & $24.8(2.5)$ & $42.8(2.9)$ & $63.6(2.6)$ & $80.8(1.4)$ \\
Sample size & 406 & 34 & 162 & 1426 \\
\hline
\end{tabular}

Parenthetical entries are standard errors.

Source: 2006 Health and Retirement Study; 2006 Medicare Beneficiary Annual Summary File.

9.1.3 inside a secure data enclave at the Institute for Social Research in Ann Arbor, Michigan. This study was exempt from Institutional Review Board oversight.

\section{Results}

First, to assess the comparability of our analytic sample we compare diabetes estimates from the linked HRSMedicare-A1c sample with those from three national samples: the 2005-2006 National Health and Nutrition Examination Survey (NHANES), the linked HRS-A1c only sample, and the linked HRS-Medicare only sample. All samples are restricted to the Medicare-eligible population aged 65 and older. Table 1 shows that the percentage of self-reported diabetics (Table 1) (21.1; 95\% CI: 19.2-23.2), clinical diabetics with A1c reading $\geq 6.5$ (12.6; 10.7-14.4), and undiagnosed diabetics (4.4; 95\% CI: 3.25.6) in the linked HRS-Medicare-A1c sample are statistically comparable to the corresponding estimates obtained from the other three samples, suggesting consistency across the sources and minimal bias in using the linked HRS-Medicare-A1c sample.

The CCW claims-based algorithm yields a significantly higher percentage of diabetes compared to self-reports (Claims: 27.3; SRs: 21.2; $p<0.05$ ). However, the overall percentage of diabetes (based on the sum of self-reported and undiagnosed diabetics) obtained from the survey data (25.6) is statistically indiscernible from the claims-based estimate (27.3; 95\% CI: 25.3-29.2).
The next analysis examines the two-way agreement between self-report and the claims-based diabetes definitions (Table 2). About 19.5 percent (or $n=406$ ) of respondents are classified as diabetic based on both self-report and claims data and 71.1 percent (or $n=1,426$ ) are classified as non-diabetics in both data sources. The remaining 9.3\% of the sample $(\mathrm{n}=196)$ yield a conflicting a result between the two measures. Most of the discordant cases (82.7 percent; $\mathrm{n}=162,7.7$ percent of total sample) are flagged as diabetic in the claims data. Discordant claims-based diabetics tend to be older and self-report better health status compared to concordant diabetics (Table 3).

Clinical classifications based on A1c readings are shown in Table 4. Not surprisingly, concordant diabetics (CDs) and concordant non-diabetics (CNDs), respectively, yield the highest and lowest percentage of clinical diabetes (A1c $\geq 6.5$ ), respectively (CDs: 45.7; CNDs: 3.5 ) among the four possible agreement groups. Among the discordant cases, self-reported diabetics yield a significantly higher mean A1c reading (6.32 vs. 5.86), a higher percentage of clinical diabetes (30.5 vs. 12.4), and a lower percentage of A1c readings less than 6.0 (42.8 vs. 63.6) relative to the CCW-based diabetics (all comparisons yield $p$-value $<0.05$ ).

Of the $4.4 \%$ of the undiagnosed sample who were classified as diabetic based on having an A1c score $\geq 6.5$, only $29.9 \%$ (95\% CI: $18.1-39.9$ ) of them were reported as being diabetic in the claims data. Thus, the claims data

Table 5 Hemoglobin A1c levels and utilization outcomes by self-report and chronic condition warehouse diabetes status

\begin{tabular}{|c|c|c|c|c|c|c|c|c|}
\hline \multirow[b]{2}{*}{$\begin{array}{l}\text { Healthcare Utilization } \\
\text { (2006) }\end{array}$} & \multicolumn{2}{|c|}{ Self-report, yes; Claims, yes } & \multicolumn{2}{|c|}{ Self-report, yes; Claims, no } & \multicolumn{2}{|c|}{ Self-report, no; Claims, yes } & \multicolumn{2}{|c|}{ Self-report, no; Claims, no } \\
\hline & $\mathrm{A} 1 \mathrm{C}<6.5$ & $\mathrm{~A} 1 \mathrm{C}>6.5$ & $\mathrm{~A} 1 \mathrm{C}<6.5$ & $A 1 C>6.5$ & A1c $<6.5$ & $\mathrm{~A} 1 \mathrm{C}>6.5$ & $\mathrm{~A} 1 \mathrm{C}<6.5$ & $A 1 C>6.5$ \\
\hline Total reimbursement & $\begin{array}{c}9400.7 \\
(1079.6)\end{array}$ & $\begin{array}{l}8770.8 \\
(1030.8)\end{array}$ & $\begin{array}{c}3275.4 \\
(1493.9)\end{array}$ & $\begin{array}{l}11823.0 \\
(8682.9)\end{array}$ & $\begin{array}{l}9383.8 \\
(1406.3)\end{array}$ & $\begin{array}{l}8613.2 \\
(2734.9)\end{array}$ & $\begin{array}{l}4731.2 \\
(320.9)\end{array}$ & $\begin{array}{l}3507.0 \\
(803.4)\end{array}$ \\
\hline Total hospitalizations & $0.39(0.05)$ & $0.36(0.06)$ & $0.19(0.10)$ & $0.32(0.17)$ & $0.34(0.06)$ & $0.47(0.14)$ & $0.23(0.02)$ & $0.15(0.07)$ \\
\hline Total office visits & $10.29(0.71)$ & $10.01(0.52)$ & $5.22(1.53)$ & $1.59(0.41)$ & $10.93(0.90)$ & $10.27(1.86)$ & $6.62(0.23)$ & $6.27(0.73)$ \\
\hline $\begin{array}{l}\text { Total A1c tests } \\
(2002-2005)\end{array}$ & $4.67(0.29)$ & $4.86(0.42)$ & $0.48(0.26)$ & $0.77(0.77)$ & $0.78(0.13)$ & $2.16(0.54)$ & $0.09(0.01)$ & $0.26(0.15)$ \\
\hline Sample size & 225 & 181 & 21 & 13 & 141 & 21 & 1377 & 49 \\
\hline
\end{tabular}


do not differ from self-report primarily because of better classification of the undiagnosed cases.

The results are suggestive that self-reports produce a more accurate indication of a diabetes diagnosis (based on clinical data) relative to the CCW algorithm. Hence, an important question to ask is whether healthcare utilization profiles are distorted by using the CCWalgorithm to identify the diabetic population.

Table 5 shows that the healthcare utilization outcomes among discordant claims-based diabetics are generally similar to that of concordant diabetics regardless of A1c levels. However, the number of A1c tests received was markedly lower for the discordant claims-based diabetics than for the concordant diabetics $(p$-value $<0.05)$. This pattern of use suggests that discordant claims-based diabetics do not receive diabetes-related care at the same rate as concordant diabetics but do receive an overall level of health services and have expenditures similar to diabetics. Regression-adjusted results (controlling for demographic characteristics) yielded the same conclusions.

\section{Discussion and conclusions}

In this study nationally-representative data linked with biomarker and Medicare claims were used to study the agreement between self-report and claims-based measures of diabetes. The claims-based CCW algorithm yielded a significantly higher rate of diabetics compared to selfreports. The biomarker data suggested that the higher rate of diabetics in the claims was due to false positives. False positives tended to be associated with high users of Medicare services with provider utilization profiles similar to those of concordant diabetics. Higher rates of diabetes prevalence in claims data may reflect intensive monitoring of pre-diabetic patients with elevated levels of other cardiovascular risk factors.

Our results raise potential concerns about attempts to use the current $\mathrm{CCW}$ diabetes indicator to identify diabetics in claims data for the purpose of assessing quality of care. Regions or accountable care organizations with high proportions of false positives may correctly fail to provide ongoing diabetes maintenance care to these patients, and thus appear to provide lower quality of care to diabetic patients (e.g., lower A1c testing).

Our findings should be interpreted in the context of the following considerations. This study relies on a single measure of Hemoglobin A1c rather than repeated measures of fasting plasma glucose or glucose tolerance test results to validate the self-report and claims-based measures of diabetes. Furthermore, people with diabetes who are controlled may have an A1c score below 6.5. We did not have access to Part D claims, though information about use of insulin or oral diabetes medications would have been another way to identify patients being treated for diabetes. However, the tradeoff would be a less representative sample as not all Medicare beneficiaries are in a stand-alone Part D plan that would have research data. Nevertheless, efforts to refine and validate claims-based algorithms with medication information may help to improve the use of these measures for health services research.

Diabetes is an important and costly chronic condition. Researchers interested in studying treatment and healthcare utilization outcomes associated with diabetes face a variety of measures to identify this subgroup. We find strengths and weaknesses of using self-reports and claims-based measures to identify the diabetic population. For researchers fortunate enough to have both measures available then the choice of which measure to use should be driven by the goals of the analysis (e.g., estimating prevalence, assessing quality of care, profiling aggregate levels of utilization) and sensitivity of the results obtained from both measures. However, if the $\mathrm{CCW}$ algorithm is the only measure available, then results should be interpreted with caution, particularly if those results pertain to diabetes prevalence and quality of care analyses.

\section{Competing interests}

The authors declare that they have no competing interests.

\section{Authors' contributions}

JWS was involved in conceptualizing the study, designing the methodology, data acquisition, analysis, data interpretation, and drafting of the manuscript. DRW was involved in conceptualization of the study, data interpretation, and drafting of the manuscript. LHN was involved in conceptualizing the study, data interpretation, and drafting of the manuscript. All authors read and approved the final manuscript.

\section{Acknowledgement}

Joseph Sakshaug received partial funding for this project from the Alexander von Humboldt Foundation. David Weir received funding for this project from the National Institute on Aging (U01AG09740). Lauren Nicholas received funding for this project from the National Center for Research Resources (UL1RR024986) and from the National Institute on Aging (101AG041763 \& U01AG09740).

\section{Author details}

${ }^{1}$ Institute for Social Research, University of Michigan, 426 Thompson Street, Ann Arbor, MI 48104, USA. ${ }^{2}$ Institute for Employment Research, Regensburger Str. 104, Nuremberg 90478, Germany. ${ }^{3}$ Health Policy \& Management, Johns Hopkins School of Public Health, 624 N. Broadway, Hampton House 450, Baltimore, MD 21205, USA.

Received: 8 January 2013 Accepted: 31 March 2014

Published: 3 April 2014

\section{References}

1. Centers for Disease Control and Prevention: National Diabetes Fact Sheet: General Information and National Estimates on Diabetes in the United States, 2007. [http://www.cdc.gov/diabetes/pubs/pdf/ndfs_2007.pdf]

2. American Diabetes Association: Economic costs of diabetes in the U.S. in 2007. Diabetes Care 2008, 31(3):596-615.

3. Fowles JB, Fowler DJ, Craft C: Validation of claims diagnoses and self-reported conditions compared with medical records for selected chronic diseases. J Ambul Care Manage 1998, 21(1):24-34

4. Gorina Y, Kramarow EA: Identifying chronic conditions in medicare claims data: evaluating the chronic condition data warehouse algorithm. Health Serv Res 2011, 46(5):1610-1627. 
5. American Diabetes Association: Standards of medical care in diabetes-2010. Diabetes Care 2010, 33(1):511-561.

6. Margolis KL, Lihong Q, Brzyski R, Bonds DE, Howard BV, Kempainen S, Liu S, Robinson JG, Safford MM, Tinker LT, Phillips LS: Validity of diabetes self-reports in the women's health initiative: comparison with medication inventories and fasting glucose measurements. Clin Trials 2008, 5(3):240-247.

7. Goldman N, Lin IF, Weinstein M: Evaluating the quality of self-reports of hypertension and diabetes. J Clin Epidemiol 2003, 56(2):148-154.

8. Dode MA, Santos IS: Validity of self-reported gestational diabetes mellitus in the immediate postpartum. Cad Saude Publica 2009, 25(2):251-258.

9. Espelt A, Goday A, Franch J, Borrell C: Validity of self-reported diabetes in health interview surveys for measuring social inequalities in the prevalence of diabetes. J Epidemiol Community Health 2012, 66(7):1-3.

10. Cowie CC, Rust KF, Byrd-Holt DD, Gregg EW, Ford ES, Geiss LS, Bainbridge KE, Fradkin JE: Prevalence of diabetes and high risk for diabetes using A1C criteria in the U.S. population in 1988-2006. Diabetes Care 2010, 33(3):562-568.

11. Losina EJ, Barrett J, Baron JA, Katz JN: Accuracy of Medicare claims data for rheumatologic diagnoses in total hip replacement recipients. J Clin Epidemiol 2003, 56(6):515-519.

12. Buccaneer, Inc: Chronic Condition Data Warehouse User Guide Version 1.8. [http://www.ccwdata.org/cs/groups/public/documents/document/ ccw_userguide.pdf]

13. Hebert PL, Geiss LS, Tierney EF, Engelgau MM, Yawn BP, McBean AM: Identifying persons with diabetes using Medicare claims data. Am J Med Qual 1999, 14(6):270-277.

14. Southern DA, Roberts B, Edwards A, Dean S, Norton P, Svenson LW, Larsen E, Sargious P, Lau DC, Ghali WA: Validity of administrative data claim-based methods for identifying individuals with diabetes at a population level. Can J Public Health 2010, 101(1):61-64.

15. Wilchesky M, Tamblyn RM, Huang A: Validation of diagnostic codes within medical services claims. J Clin Epidemiol 2004, 57:131-141.

16. Miller DR, Safford MM, Pogach LM: Who has diabetes? Best estimates of diabetes prevalence in the Department of Veterans Affairs based on computerized patient data. Diabetes Care 2004, 27(Suppl. 2):B10-B21.

17. Juster FT, Suzman R: An overview of the Health and Retirement Study. J Hum Resour 1996, 30(5):S7-S56.

18. Keating NL, Landrum MB, Landon BE, Ayanian JZ, Borbas C, Guadagnoli E: Measuring the quality of diabetes care using administrative data: is there bias? Health Serv Res 2003, 38(6, Part I):1529-1546.

19. Grant RW, Buse JB, Meigs JB: Quality of diabetes care in U.S. academic medical centers: low rates of medical regimen change. Diabetes Care 2005, 28(2):337-442

20. Chin MH, Auerbach SB, Cook S, Harrison JF, Koppert J, Jin L, Thiel F, Karrison TG, Harrand AG, Schaefer CT, Takashima HT, Egbert N, Chiu SC, McNabb WL: Quality of diabetes care in community health centers. Am J Public Health 2000, 90(3):431-434.

21. Saaddine JB, Engelgau MM, Beckles GL, Gregg EW, Thompson TJ, Narayan KM: A diabetes report card for the United States: quality of care in the 1990s. Ann Intern Med 2002, 136(8):565-574.

doi:10.1186/1472-6963-14-150

Cite this article as: Sakshaug et al.: Identifying diabetics in Medicare claims and survey data: implications for health services research. BMC Health Services Research 2014 14:150.

\section{Submit your next manuscript to BioMed Central and take full advantage of:}

- Convenient online submission

- Thorough peer review

- No space constraints or color figure charges

- Immediate publication on acceptance

- Inclusion in PubMed, CAS, Scopus and Google Scholar

- Research which is freely available for redistribution

Submit your manuscript at www.biomedcentral.com/submit
C BioMed Central 